\title{
A Study on the Absence of Palmaris Longus in a Multi- racial Population
}

\author{
SA Roohi, MS (Ortho) (UKM), L Choon-Sian, MD (UKM), A Shalimar, MS (Ortho) (UKM), \\ GH Tan, MS (Ortho) (UKM), AS Naicker, M Med Rehab (UM) \\ Hospital Universiti Kebangsaan Malaysia, Kuala Lumpur, Malaysia
}

\begin{abstract}
Palmaris longus is a dispensable muscle with a long tendon which is very useful in reconstructive surgery. It is absent 2.8 to $24 \%$ of the population depending on the race/ethnicity studied. Four hundred and fifty healthy subjects (equally distributed among Malaysia's 3 major ethnic groups) were clinically examined for the presence or absence of palmaris longus. This tendon was found to be absent unilaterally in $6.4 \%$ of study subjects, and bilaterally in $2.9 \%$ of study participants. Malays have a high prevalence of palmaris longus absence at $11.3 \%$ followed closely by Indians at $10.7 \%$ whilst Chinese had a low absence rate of $6.0 \%$.
\end{abstract}

\section{Key Words: \\ Palmaris longus, Chinese, Malaysian, Indian, Hand surgery, Tendon}

\section{INTRODUCTION}

Palmaris longus muscle is located between flexor carpi radialis and flexor carpi ulnaris muscles. It is slender, fusiform in shape and arises from the common flexor origin around the medial epicondyle. It ends as a slender, flattened tendon passing superficially over the transverse carpal ligament and inserting into the palmar aponeurosis.

The action of palmaris longus is to weakly flex the wrist and tense the palmar aponeurosis, synergised by flexor carpi radialis, flexor carpi ulnaris and flexor digitorum superficialis. The presence of palmaris longus is readily demonstrated by Schaeffer's test ${ }^{1}$ where the wrist is slightly flexed with the thumb and little finger opposed (Fig 1). It is supplied by the median nerve. Palmaris longus is considered to be a dispensable tendon because its absence does not significantly affect the function of the wrist. It is therefore very useful in orthopaedic, hand and reconstructive surgery. It is commonly used by hand surgeons for tendon transfers, second stage tendon reconstruction, pulley reconstruction as well as tendon grafts. Plastic surgeons also utilise the palmaris longus in restoration of lip and chin defects ${ }^{2}$.
Most standard textbooks of hand surgery quote the prevalence of absence of palmaris longus at around $15 \% 0^{3-5}$. However, this figure varies considerably in different ethnic groups. A study by Thompson et $a l^{6}$ on 300 Caucasian subjects found that palmaris longus was absent unilaterally in $16 \%$, and bilaterally in $9 \%$ of the study sample for an overall prevalence of absence of $24 \%$. Similarly, George ${ }^{7}$ noted on 276 cadavers of European descent that its absence was 13\% unilaterally, $8.7 \%$ bilaterally for an overall absence of $15.2 \%$. Another cadaveric study by Vanderhooft ${ }^{8}$ in Seattle, USA reported its overall absence to be $12 \%$. Sebastin et al ${ }^{9}$ recently studied 329 Chinese subjects in Singapore and found that palmaris longus is absent unilaterally in $3.3 \%$, bilaterally in $1.2 \%$ with an overall absence of $4.6 \%$. This revealed a much lower prevalence of absence in Chinese subjects as compared to Caucasians.

Malaysia has a multiracial population comprises of 3 major ethnic groups: Malays (60\%), Chinese (30\%) and Indians $(10 \%)$. Although all of these ethnic groups are considered Asian, the Malays originated from Polynesian or Melanesian stock, the Chinese from mainland China whilst the Indians from the Indian subcontinent. The aim of this study is to determine the rate of absence of palmaris longus and to compare its distribution amongst the races in Malaysia.

\section{MATERIALS AND METHODS}

This is a cross sectional study that involved 450 healthy subjects seen at our institution. Since there are 3 main races and 2 genders, we estimated that a minimum of 50 patients will be required in each group to provide significant comparison. We therefore recruited 75 subjects in each arm of this study. We excluded subjects with physically disabilities (including those resulting from trauma, be it spine, lower or upper limb), any prior surgery (to upper or lower limbs) and any upper limb injuries.

Each subject was asked to complete a general identification questionnaire and examined for the palmaris longus. This is achieved by clinical inspection of the volar aspect of the 
Table I: Age groups of the subjects

\begin{tabular}{|llllllll|}
\hline Age group & $11-20$ & $21-30$ & $31-40$ & $41-50$ & $51-60$ & $61-70$ & Total \\
\hline $\mathrm{N}$ & 47 & 154 & 74 & 83 & 64 & 28 & 450 \\
$\%$ & 10.4 & 34.2 & 16.5 & 18.5 & 14.2 & 6.2 & 100 \\
\hline
\end{tabular}

Table II: Frequency of Absence of Palmaris Longus

\begin{tabular}{|lcc|}
\hline & Absence & Number \\
\hline Unilateral & $29(6.4 \%)$ & 29 \\
Bilateral & $13(2.9 \%)$ & 421 \\
Total & $42(9.3 \%)$ & 450 \\
\hline
\end{tabular}

Table III: Frequency of Absence of Palmaris Longus among ethnic groups

\begin{tabular}{|c|c|c|c|c|c|}
\hline & Present bilaterally & & & Total & \\
\hline & & Unilateral & Bilateral & & \\
\hline Malay & $133(88.7 \%)$ & $12(8.0 \%)$ & $5(3.3 \%)$ & $150(100 \%)$ & $\chi 2=2.994$ \\
\hline Chinese & $141(94.0 \%)$ & $7(4.7 \%)$ & $2(1.3 \%)$ & $150(100 \%)$ & $p=0.224$ \\
\hline Indian & $134(89.3 \%)$ & $10(6.7 \%)$ & $6(4.0 \%)$ & $150(100 \%)$ & \\
\hline
\end{tabular}

Table IV: Frequency of Absence of Palmaris Longus between genders

\begin{tabular}{|llllll|}
\hline & Present bilaterally & \multicolumn{3}{c}{ Absent } & Total \\
\cline { 2 - 4 } & & Unilateral & Bilateral & & \\
\hline Male & $209(92.9 \%)$ & $13(5.8 \%)$ & $3(1.3 \%)$ & $225(100 \%)$ & $\times 2=2.626$ \\
Female & $199(88.5 \%)$ & $16(7.1 \%)$ & $10(4.4 \%)$ & $225(100 \%)$ & $\mathrm{p}=0.105$ \\
\hline
\end{tabular}

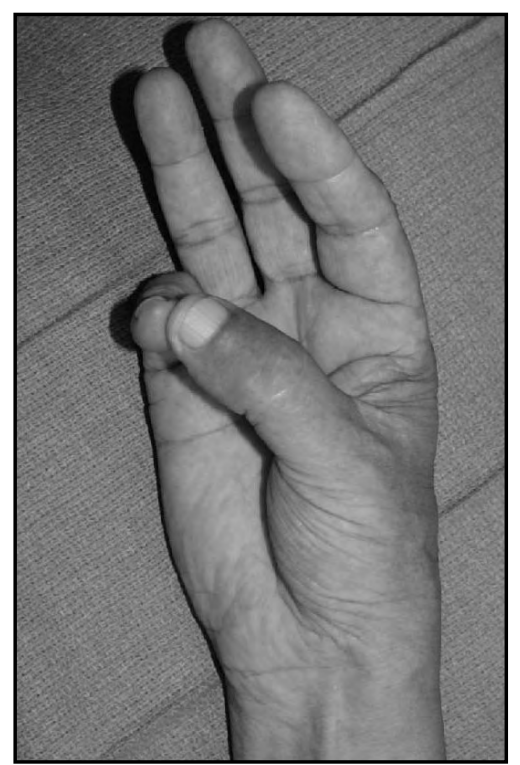

Fig. 1: Schaeffer's test demonstrating the presence of palmaris longus.

wrist and by performing Schaeffer's test (slight wrist flexion with thumb and little finger opposed).

The associations between absence of palmaris longus and ethnic group, gender and body side were assessed using chisquare tests using a statistical significance of $\mathrm{p}<0.05$.

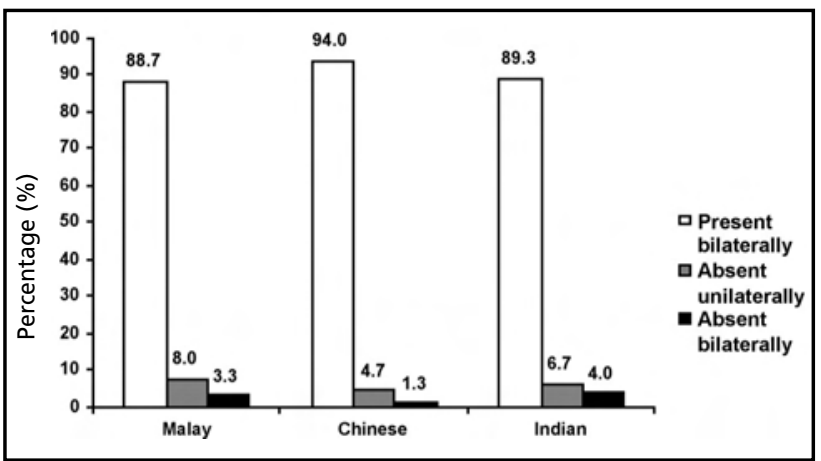

Fig. 2: Absence of palmaris longus amongst the multi-racial Malaysian population.

\section{RESULTS}

Of the 450 subjects participated in this study, exactly half were male and half were female. The subjects were also equally divided between the 3 major races in Malaysia: the Malays, Chinese and Indians with each race comprising 150 subjects (33.3\%). Most of the subjects were between 21 and 30 years old. (Table I).

Palmaris longus was found to be absent unilaterally in 29 $(6.4 \%)$, bilaterally in $13(2.9 \%)$, with an overall absence in 42 subjects $(9.3 \%)$ (Table II). Amongst the races, Malays had the highest percentage of palmaris longus absence $(11.3 \%)$, followed by the Indians at $10.7 \%$ and finally, the Chinese at $6.0 \%$ (Fig. 2). Detailed results and chi-square values are presented in Table III. 


\section{DISCUSSION}

It is clear that prevalence of absence of palmaris longus varies depending on the populations. Caucasians have a high rate of absence which is between $12-24 \%^{6-8}$ whilst Singaporean Chinese have a low rate of absence $(4.6 \%)^{9}$. In another study of a Chinese population by Wagenseil the figure was cited as $2.8 \%$ while Amazon Indians were noted to have a $3.7 \%$ absence of palmaris longus ${ }^{10}$.

Our study revealed varying figures for each ethnic group. The Malays have a prevalence of palmaris longus absence of $11.3 \%$ followed by the Indians at $10.7 \%$ and the Chinese at $6.0 \%$. Lower rate in Chinese population corresponded with other studies ${ }^{9,10}$. However, the differences were not statistically significant $(\mathrm{p}=0.224)$. We found that in total, as a multiracial population, the overall absence in Malaysians of palmaris longus is $9.3 \%$. It is interesting to note that most reports in literature quote a figure of about $15 \%$ which is more akin to Caucasian values ${ }^{3-5}$.

Numerous studies indicated that absence of palmaris longus is more common in women and on the left side, although the differences were usually not significant when analyzed statistically ${ }^{6,8,11}$ Our study showed similar findings and again the differences were not significant.

Patients who do not have a palmaris longus may need to use the plantaris as an alternative donor graft. Based on studies conducted in Caucasian population, there was no relationship or association between the absence of these two muscles ${ }^{7,8}$.

\section{CONCLUSION}

In Malaysia, palmaris longus is absent unilaterally in $6.4 \%$ and bilaterally in $2.9 \%$ of its population with an overall absence of $9.3 \%$. The rate is lower than Caucasians which varies from $12-24 \%$. Malays had a prevalence of palmaris longus absence at $11.3 \%$ followed closely by the Indians at $10.7 \%$ whilst the Chinese had the lowest absence rate of $6.0 \%$. The palmaris longus was found to be absent three times more frequently on the left than the right and slightly more frequently in females than males.

\section{REFERENCES}

1. Schaeffer JP. On the variations of the palmaris longus muscle. Anat Rec 1909;3:275-8.

2. Carroll CM, Pathak I, Irish J, Neligan PC. Reconstruction of total lower lip and chin defects using the composite radial forearm-palmaris longus tendon free flap. Arch Facial Plast Surg 2000; 2(1):53-6.

3. Kleinert HE, Pulvertaft RG, Smith DJ. Flexor tendon grafting in the hand. In: Jupiter JB, editor. Flynn's Hand Surgery. Baltimore: Williams \& Wilkins. 1991: 285.

4. Zancolli EA, Cozzi EP. The retinaculum cutis of the hand. In: Zancolli EA, Cozzi EP (eds). Atlas of Surgical Anatomy of the Hand. New York: Churchill Livingstone, 1992: 2.

5. Valentine P. Extrinsic muscles of the hand and wrist: An Introduction. In: Tubiana R (ed). The Hand. Vol I. Philadelphia: WB Saunders, 1981: 237.

6. Thompson NW, Mockford BF, Cran GW. Absence of the palmaris longus muscle: a population study. Ulster Med J 2001; 70: 22-4

7. George R. Co-incidence of the palmaris longus and plantaris muscles. Anat Rec 1953; 116: 521-3.

8. Vanderhooft $\mathrm{E}$. The frequency and relationship between the palmaris longus and plantaris tendons. Am J Orthop 1996; 25:38-41.

9. Sebastin SJ, Lim AYT, Wong HB. Clinical Assessment of Absence of the Palmaris Longus and its Association With Other Anatomical Anomalies - A Chinese Population Study. Ann Acad Med Singapore 2006; 35: 249-5.

10. Machado AB, DiDio LJ. Frequency of the musculus palmaris longus studied in vivo in some Amazon Indians. Am J Phys Anthrop 1967; 27: 11-20.

11. Troha R, Baibak GJ, Kelleher JC. Frequency of the palmaris longus tendon in North American Caucasians. Ann Plat Surg 1990; 25: 477-8. 